this is a splendid book for discovering what is new. It will enthral some computer scientists and provoke some philosophers. And it should engage general readers who wish to enjoy a clear, understandable description of many advanced principles of computer science.

Igor Aleksander is emeritus professor and Leverhulme fellow in intelligent systems and networks at Imperial College, London SW7 2BT, UK. He is writing Five Steps to Being Conscious: the Inner Life of People, Animals and Machines.

\section{Split decision}

\section{The Fly in the Cathedral: How a Small Group of Cambridge Scientists Won the Race to \\ Split the Atom \\ by Brain Cathcart \\ Viking: 2004. 320 pp. $£ 14.99$}

\section{Frank Close}

If an atom were expanded to the size of a cathedral, its nucleus would be the size of a fly. Ernest Rutherford deduced the existence of this atomic 'fly' some 90 years ago, but the challenge of illuminating its mysteries and determining its make-up seemed to be beyond reach. Then, after years of effort, two young researchers, John Cockcroft and Ernest Walton, under Rutherford's guidance, built their eponymous accelerator in a basement at the Cavendish Laboratory in Cambridge, UK. In 1932 the media heralded their triumph with a phrase that has rung through the ages: "The atom split". The age of accelerators and big science had arrived. The Fly in the Cathedral tells the story of how this came to be.

Books about theoretical physics abound; those about experiments are thinner on the ground. The Fly in the Cathedral is indeed a rarity in focusing on how a classic experiment came about. The book's strength is that it reveals the nature of science - in particular how inspiration is partner to vast amounts of perspiration, commitment and dedication.

Rutherford discovered the existence of the atomic nucleus by scattering alphaparticles from it. No one knew how a positively charged alpha-particle managed to survive inside the atom along with all the other positive charges. But they knew that some were ejected "as if hurled by a catapult" at tremendous speed, thanks to repulsive electric forces. It was by scattering these natural bullets from atoms that Rutherford came to discover the atomic nucleus. To understand how the nucleus was constructed, it would be necessary for beams of alpha-particles to penetrate it, but first they would have to be given even higher energies to overcome the huge electrical barrier. An

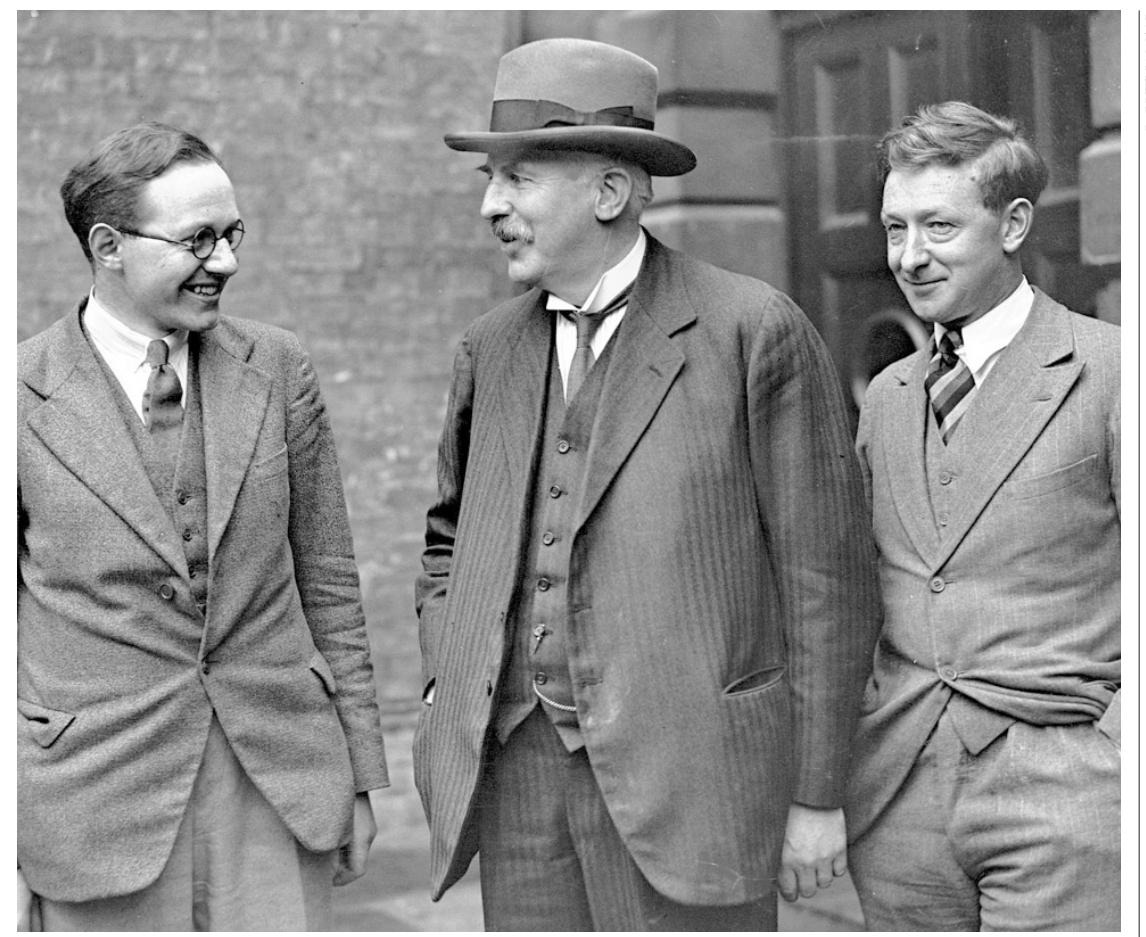

Ernest Rutherford (centre) helped Ernest Walton (left) and John Cockcroft to split the atom.

accelerator powered with millions of volts was needed. This was what Cockcroft and Walton set out to make.

Quantum mechanics came to the rescue. George Gamow showed that alpha-particles could be trapped within a huge potential barrier inside the nucleus and that, according to quantum mechanics, there was a chance that the alpha-particles could 'tunnel' through it and escape. His beautiful exposition is now a standard example in undergraduate quantum-mechanics courses. A good idea is rarely yours alone, though, and Gamow was beaten into print by Edward Condon and R. W. Gurney, even though their letter was dated one day after his. His fortune was that he came to the attention of Rutherford, which in turn led to his move to Cambridge.

Gamow gained his own priority, though, with a seminal paper in Nature in which he turned the original question on its head. Instead of discussing how particles manage to escape from the nucleus, he looked at how they might get in. Quantum mechanics enables alpha-particles to penetrate the potential Coulomb barrier without the need for them to be accelerated to huge energies. Cockcroft realized that if protons were used instead of alpha-particles, things would be even better. Instead of millions of volts, as they had originally thought, as little as 300,000 volts might be enough. This opened the way for the experimental study of nuclear physics.

In Cambridge, Cockcroft and Walton were hard at work building their device. In the United States, Ernest Lawrence was building the first cyclotron. This promised far greater energies than Cockcroft and Walton's device, but Lawrence's claims were based more on hope than realization. The pace of Brian Cathcart's narrative slows somewhat when describing the details of Cockcroft and Walton's efforts, but the slightly ponderous tone at this point is a metaphor for what actually happened: Cockcroft and Walton seemed obsessed with building and improving their machine until Rutherford one day insisted that they actually put it to work.

Suddenly the story comes alive again. Gamow's estimates, which everyone was treating with caution and aiming to beat, turned out to be conservative. Protons would invade a nucleus at relatively moderate energies easily within the reach of Cockcroft and Walton's device. It transpired that they could have achieved their results with the prototype accelerator they built some three years earlier. The rest, as they say, is history.

In addition to the history, it is unusual to see the portraits, both literal and visual, of the protagonists and appreciate their commitment to seeing the task through. For all the hyped speculation about superstrings, higher dimensions and theoretical science that borders fact and fiction, it is good to see books such as The Fly in the Cathedral, which remind us that it is ultimately experiment that decides. And that creating tools to expand our senses can provide a fascinating and dramatic story.

Frank Close is at Exeter College and the Rudolf Peierls Centre for Theoretical Physics, 1 Keble Road, Oxford University, Oxford OX1 3NP, UK. 